\title{
Adipose Tissue and Inflammation
}

\author{
José Luis Muñoz Carrillo, \\ Jaime Ortega Martín Del Campo, \\ Oscar Gutiérrez Coronado, \\ Paola Trinidad Villalobos Gutiérrez, \\ Juan Francisco Contreras Cordero and \\ Javier Ventura Juárez
}

Additional information is available at the end of the chapter

http://dx.doi.org/10.5772/intechopen.74227

\begin{abstract}
Adipose tissue is composed mainly by adipocytes and stromal-vascular fraction, which are composed by different cell types including macrophages. There are three types of adipose tissue: brown (BrAT), white (WAT), and beige (BeAT). BrAT is less abundant and is implicated in lipid oxidation and energy balance; BeAT has the pathway of adaptive thermogenesis, and WAT is endocrine in nature and lipid storage site and is implicated as an endocrine organ that secretes hormones and different molecules. These molecules are pro-inflammatory and anti-inflammatory factors, including the adipokines leptin, adiponectin, resistin, and visfatin, as well as cytokines and chemokines, such as tumor necrosis factor (TNF)- $\alpha$, interleukin (IL)-6, leptin, adiponectin, and others, are involved with the development of adipose tissue inflammation and obesity. This pathological condition, together with other factors such as oxidative stress, may develop insulin resistance and the pathogenesis of type 2 diabetes mellitus (T2DM).
\end{abstract}

Keywords: adipose tissue, inflammation, oxidative stress, insulin resistance, type 2 diabetes mellitus

\section{Introduction}

Adipose tissue at first considered as a fat storage and insulation organ had a radical change when leptin, the hormone of obesity, was discovered [1]. Since then, the adipose tissue has gained more interest to know its role as an endocrine tissue and its capacity of producing 
other molecules that have action in various parts of the body including metabolic regulation and the immune system. Adipose tissue is composed primarily by pre-adipocytes and adipocytes, but other types of cells called the stromal-vascular fraction composed by different cell types including macrophages, neutrophils, lymphocytes, fibroblast, and endothelial cells among others also are present [2]. The presence of these cells account for the vast secretion of molecules called adipokines with various significant physiological functions, many of them implicated in metabolism and others implicated in the balance between pro- and antiinflammation to maintain the homeostasis. In obesity, there is a strong inflammatory response in adipose tissue, which is one of the most important causes for the development of insulin resistance and the pathogenesis of T2DM.

\section{Morphology and physiology of adipose tissue}

The adipose tissue originates from the mesenchymal cells and around the blood vessels in the 14th and 24th week of embryonic development. In the late stage, fibrous and vascular septa are formed between the aggregates of lipocytes that appear in the face, neck, breast, and abdominal wall at 14 weeks, and at 15 weeks, it is already evident in the back and the shoulder, later extending to limbs, higher and lower at 23 weeks. There is an excellent association between adipogenesis and angiogenesis, since lipoprotein-lipase accumulates in the lipocyte membrane, which transfers serum lipoproteins to lipocytes [3].

There are three types of adipose tissues: brown, white, and beige. They differ in development, anatomical location, and species. BrAT is less abundant and is implicated in lipid oxidation [2], and also has a great potential of impact on the energy balance. It is capable of rapidly producing large quantities of heat through the activation of the only uncoupling protein (UCP)-1 located in the mitochondria inner membrane. WAT is endocrine in nature and lipid storage site and is implicated as an endocrine organ that secretes hormones and different molecules as growth factors, complement factors, enzymes, and pro- and anti-inflammatory cytokines among others [2]; while BeAT is primarily white, it has some cells that have UCP-I. BrAT appears first in the fetus mid-gestation and is lost during the maturation of childhood, adolescence, and mature age [4].

\subsection{White adipose tissue}

Histology: the preadipocyte is spindle-shaped with $4-5$ cell extensions and abundant rough endoplasmic reticulum (ER). Adipocyte of WAT is a spherical cell with variable size from 10 to $180 \mu \mathrm{m}$ diameter depending of the content of the unique fat droplet (red arrow in Figure 1A) [5]; each fat cell is surrounded by its membrane, the center is occupied by a single-lipid vacuole, the cytoplasm is at the periphery as a rim, the nucleus is in flattened form and have a clear vacuole; in the rim of cytoplasm (arrowhead in Figure 1B), the tissue is subdivided into incomplete lobules by slim bands of collagen forming the stroma, in which there are several blood vessels (black arrow in Figure 1A), in the external membrane of endotelial cells of blood vessels are the lipoprotein lipase to translate free fatty acids to adipocyte increasing like this the vacuole of lipid [4]. 
A

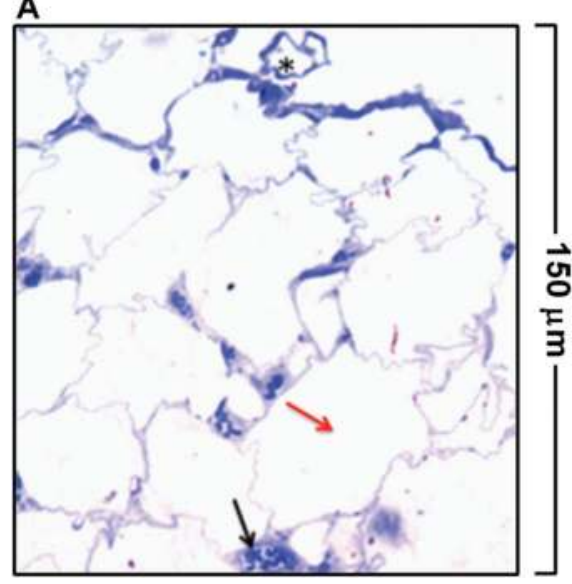

B

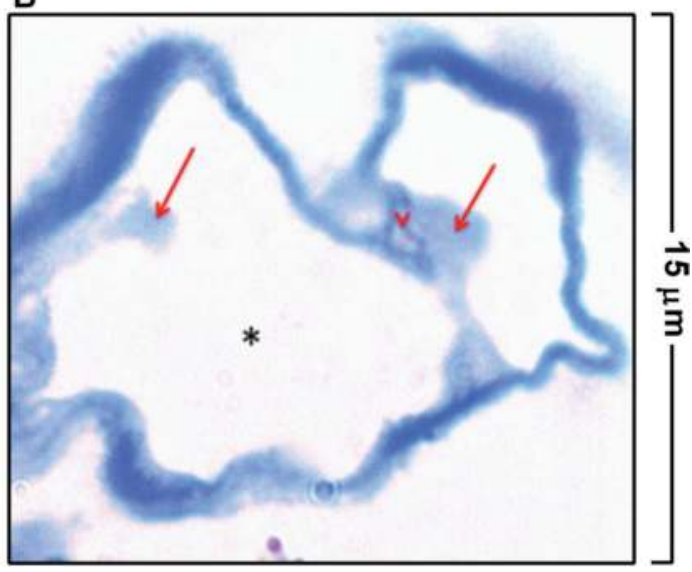

Figure 1. Photomicrography of white adipose tissue. (A) Photomicrography of WAT-150 $\mu \mathrm{m}$. The red arrow shows the unilocular fat cell, cytoplasm. The black shows blood vessel. (B) Photomicrography of WAT-15 $\mu \mathrm{m}$. The red arrows show the nucleus. V: blood vessel. Toluidine blue stain in L.R. White resin.

The capacity of storing fat during excess food intake enables the organism to use this fat as energy source in starvation condition or in significant energy expenditure. However, as mentioned above, the adipocytes also produce and secrete different molecules. Some of them act as hormones or likehormones with actions related to the storage or utilization of fat, while other molecules produced by adipocytes play a role directly connected to the immune system in both innate and adaptive response. All these activities change the notion that adipocyte is merely a cell to store or release energy to a dynamic system of metabolic regulation as well as immune defense mechanism [6].

\subsection{Brown adipose tissue}

Histologically, BrAT is organized into lobules formed by fat cells surrounded by collagen bands mixed with capillaries, nerves, and connective tissues. In BrAT, in the cells, the lipid droplets accumulate in multiple vesicles and therefore appear as multivesicular (red arrow in Figure 2A) intermixed with abundant mitochondria, given to the cytoplasm a multigranular shape surrounding the prominent central nucleus (red arrow in Figure 2B). In some brown fat cells, the lipid gathers, then the droplets coalesce into a large vacuole that gives the cell first an oval and finally round shape as unilocular cell (asterisk in Figure 2A). The cells are polygonal in shape with a mixture of multivacuolated and univacuolated cells.

Brown adipose cells are surrounded by a network of collagen fibers that contain abundant minute sympathetic nerves and blood vessels. Non-myelinated axons terminate in fat cells, providing for a direct sympathetic regulation, and the vascularity is ample with numerous capillaries coursing between the adipocytes [4]. Brown adipose cells have numerous mitochondria that participate in heat production through UCP-1 protein. This protein is located in the inner mitochondrial membrane where it is responsible for uncoupling of adenosine5'-triphosphate (ATP) production to use the conductance of $\mathrm{H}+$ gradient to produce heat [7]. 

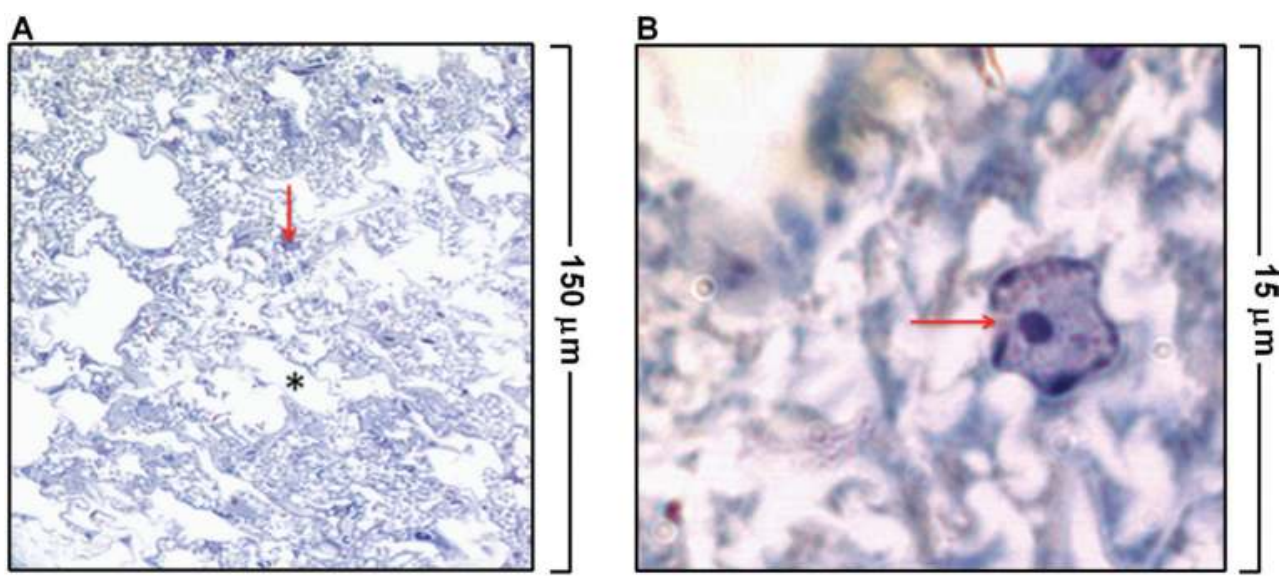

Figure 2. Photomicrography of Brown adipose tissue. (A) Photomicrography of BrAT-150 $\mu \mathrm{m}$. The red arrow shows the multilocular fat cell and nucleus. The asterisk shows an unilocular fat cell. (B) Photomicrography of BrAT-15 $\mu \mathrm{m}$. Red arrow shows the nucleus. Toluidine blue stain in L.R. White resin.

\subsection{Beige adipose tissue}

The BeAT is very similar histologically to BrAT; despite these similarities, it is now clear that the "classical" brown fat cells and the inducible "beige" fat cells come from different developmental lineages and are, in fact, distinct cell types; however, BeAT have the pathway of adaptive thermogenesis which is activated by cold via, and indirect pathway mediated by the sympathetic nervous system. Additionally, fat cells are also able to directly sense cold. The thermogenesis that is carried out in the Beige tissue is also by the UCP-1 protein. As mentioned above, this protein decouples the protons that would be used in the respiratory chain, thus transporting to heat producing in the inner membrane of the mitochondria instead of producing ATP; in this way, the chemical energy of the lipids and carbohydrates is released as heat and not by the formation of ATP [8].

This form of heat formation by adipocytes contributes to metabolic homeostasis, since the partial elimination of the UCP-1 protein in transgenic strains of mice is more susceptible to obesity and diabetes. Likewise, the total absence of the UCP-1 protein considerably increases the weight and fat content, which is demonstrated in the total absent mouse model of the forkhead box protein (FOX)-C2; these mice were induced to diabetes and obesity with considerable increase in brown and beige fat [8].

\subsection{Genetics}

At birth, there is approximately $16 \%$ of adult fat, and it is proliferating until puberty; from this the fatty tissue does not increase in volume except in exceptional cases of overfeeding, or slightly decreases in cases of strict diets of food reduction. The differentiation of adipocytes is controlled by the CHOP gene, which encodes a protein CCAAT/enhancer protein (C/CEBP), which also controls the differentiation of fibroblasts to adipocytes [4]. 


\subsection{Physiology}

White fat serves as a thermal insulator and protector of underlying tissues, and is essential in the uptake, synthesis, and storage of lipids and release of fatty acids in response to various neuronal and hormonal stimuli. This function is regulated by the hormone adipocyte lipoprotein lipase (LPL) which is increased in obesity and decreases with periods of lack of nutrition (starvation) and in diabetes. Insulin inhibits hormone-sensitive lipase and therefore blocks the release of fatty acids. It also serves to promote the uptake of glucose by adipocytes which are the precursor of glycerol phosphate, which in turn is necessary for the synthesis of triglycerides. Adipocytes have alpha and beta-adrenergic receptors; B1 adrenoreceptor agonists stimulate lipolysis, while alpha2 inhibitors inhibit it, both work through the cAMP as the second messenger. There are bodily differences, in some women there is a predominance of alpha 2 receptors in fat tissue of the gluteal region; therefore, although they are thin in other parts of the body, this gluteal region does not undergo changes in the fat content; on the other hand, some other people have more LPL, and based on the above, we can see that different body regions have different amounts of LPL receptors and alpha and beta-adrenergic receptors, which allow different deposits of fat in men and women. Growth hormone, insulin, glucocorticoids, and estradiol-17 $\beta$ stimulate the synthesis of DNA in adipocytes of both men and women [3].

\section{Molecules secreted by adipocytes and stromal-vascular fraction}

Although TNF- $\alpha$, a potent pro-inflammatory cytokine $[9,10]$ was the first cytokine discovered that is secreted by adipose tissue [11], the leptin was the first molecule with hormonal activity that is secreted by adipocytes. Since then, multiple molecules called adipokines have been discovered as factors that are secreted by adipocytes or by the stromal-vascular fraction, composed mainly by macrophages, neutrophils, lymphocytes, fibroblast, and endothelial cells. This knowledge gave evidence that the adipose tissue modules various parts of the body and it is now considered as an organ endocrine, paracrine, or autocrine secreting molecules with activities as hormones, grow factors, chemotactic molecule, enzymes, and pro- and antiinflammatory factors $[12,13]$.

\subsection{Hormones}

Adipocytes are cells metabolically dynamic that secrete multiple hormones that regulate the homeostasis. Leptin, acylation stimulating protein (ASP), adiponectin, resistin, and visfatin are hormones produced and secreted by adipocytes. These hormones play a key role over regulatory functions of various mechanisms such as beta-oxidation, fatty acid synthesis, and energy metabolism [14, 15]. Leptin is a hormone that suppresses food intake, and the gene that encodes this hormone is called obesity gene. Adiponectin is implicated in the metabolism of glucose and fatty acids. Acylation stimulating protein is concerned with fat-store. Resistin is a hormone implicated in resistance of insulin, and visfatin is a hormone with implication in the utilization of glucose. However, these hormones also are implicated in inflammation process 
and they can interact with cells of the innate and adaptive immune system modulating the production of cytokines from adipocytes and the stromal-vascular fraction [16, 17] (Figure 3).

\subsection{Growth factors}

Fibroblast growth factors (FGFs), insulin-like growth factor (IGF)-1, hepatocyte growth factor (HGF), nerve growth factor (NGF), vascular endothelial cell growth factor (VEGF), and transforming growth factor (TGF)- $\beta$ are growth factors that also can be produced by adipose tissue, and they can induce the adipogenesis [18], glucose metabolism [19], angiogenesis [20, 21] and thermogenesis [22]. However, they can also be implicated in inflammation processes (Figure 3).

\subsection{Cytokines}

There are many cytokines implicated in inflammation and there are differences in cytokine type according the individual status. The cytokines can be classified as pro-inflammatory or anti-inflammatory, although depending on the condition, some cytokines overlap both pro- and anti-inflammatory function. Also, depending on the condition of the body diverse

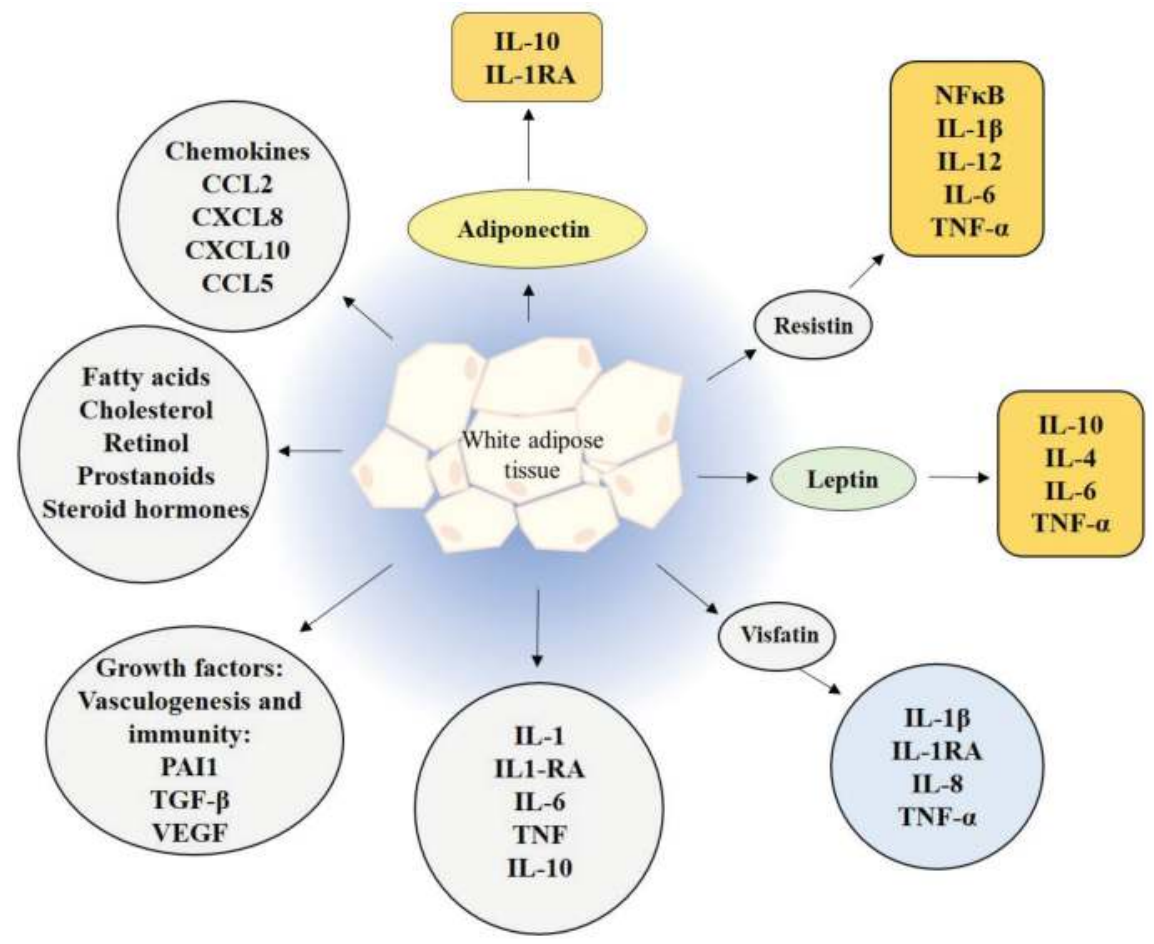

Figure 3. Adipokines secreted by adipose tissue linked to metabolic regulation and immune response. CCL, CC-chemokine ligand; CXCL, CXC-chemokine ligand; IL, interleukin; IL1-RA, interleukin-1-receptor antagonist; NGF, nerve growth factor; PAI-1, plasminogen activator inhibitor 1; TNF, tumor necrosis factor; VEGF, vascular endothelial growth factor. Description in the text. 
types, cytokines can be produced; for example, in lean condition, IL-10, IL-4, IL-13, and IL-1 receptor antagonist (IL-Ra) are commonly produced and these cytokines exert anti-inflammatory function. On the contrary, obese individuals mainly produce and secrete IL-1, TNF- $\alpha$, and IL-6 implicated in the inflammatory process $[23,24]$. Although there are other cytokines produced by the adipocytes as Leukemia inhibitory factor, interferon (INF)- $\alpha$, IL- 6 , and transforming growth factor (TGF)- $\beta$ that can function as both pro-inflammatory and antiinflammatory cytokines [25].

\section{Relationship among adipokines and immune system}

The relationship among adipokines with the immune response is complex. In addition to adipocytes, other cells are necessary in adipose tissue to exert its function. Cells like macrophages and lymphocytes can infiltrate the adipose tissue. There is a difference over the presence of these cells among individuals and the cell number is proportional to the size of the adipocytes. There is more infiltration of macrophages and lymphocytes in obese individual than normal individuals. Even more, there is a significant difference considering the base line number of these cells in normal individuals compared with the number observed in starvation and obese individuals [26, 27].

In the last 25 years, the relationship between adipose tissue and immune response has been extensively studied. The innate response with the production of pro-inflammatory cytokines is the main activity detected in adipocytes in normal condition. Macrophages are the main cell in adipose tissue that produces the first adipokines linking the innate and adaptive response. In normal condition, there is a homeostasis with different number of cytokines produced by macrophages mainly anti-inflammatory factors. In lean condition, macrophage population consist of M2 phenotype producing anti-inflammatory cytokine, whereas in obese condition, the macrophages are classically activated producing pro-inflammatory cytokine with increasing levels of TNF- $\alpha$ that exert multiples effects in different cells population around the body (Figure 4) [28].

The macrophages in adipose tissue have two origins. First, there is evidence that there exists a macrophage resident population established since embryonic development [29], and other population are monocyte-derived macrophages that respond to the inflammation process [30]. However, the population of macrophages that respond in the inflammation process is originated from circulating monocytes. In this initial process of inflammation, death adipocytes are capable to attract macrophages and depending of the type of cell death is the type of cytokine produced: apoptotic cells establish the production of anti-inflammatory cytokine, whereas necrotic cell establish a pro-inflammatory cytokine production characterized by the secretion of IL-1 from the macrophages population [31, 32]. Also, exogenous or endogen fatty acid as well as exogenous lipopolysaccharide are capable of inducing inflammation in adipose tissue through the activation of toll-like receptors present in both adipocytes and macrophages. However, the factors produced by the adipose tissue, both hormones and cytokines, have effect over other cell types including lymphocytes, dendritic cells, and neutrophils among others, affecting different mechanisms related with the production and release of multiple cytokines of the innate and adaptive response [16, 17, 33] (Figure 4). Now, the functionality 


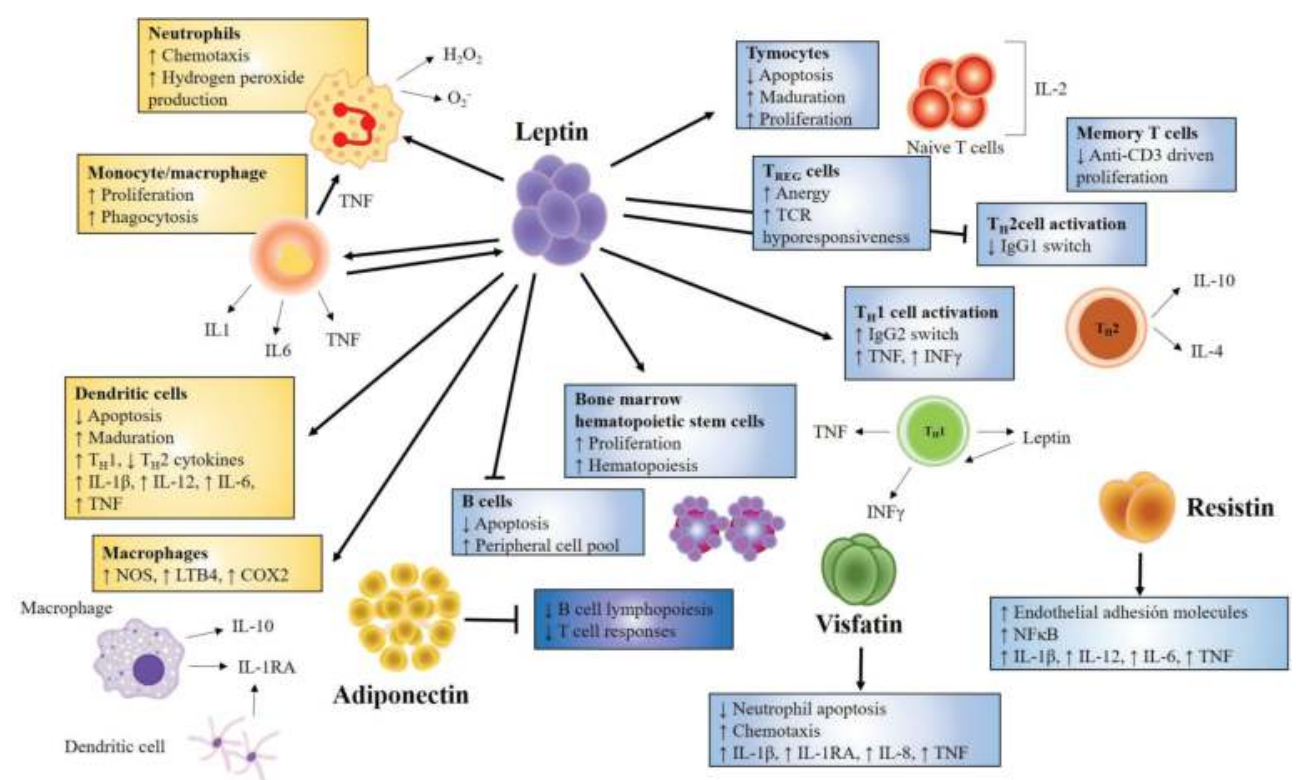

Figure 4. Adipokines and innate and adaptive response. Factors secreted by adipose tissue modulate various immunological process including activation and inactivation of leucocytes, and cell apoptosis, linking the innate and adaptive response. COX-2, cyclo-oxygenase 2; HMW, high molecular weight; IgG, immunoglobulin G; IFN, interferon; IL, interleukin; LTB-4, leukotriene B4; NFkB, nuclear factor $\kappa B$; NOS, nitric oxide synthase; TCR, T-cell receptor; Th, helper $\mathrm{T}$ cell; $\mathrm{TNF}$, tumor necrosis factor; $\mathrm{T}_{\mathrm{REG}}$, regulatory $\mathrm{T}$ cell. Description in the text.

of the adipose tissue under obesity condition have gained considerable interest mainly by its relationship with different diseases including diabetes, cardiovascular disease, metabolic syndrome, and its possible association with joint diseases [34, 35].

\section{Relationship of obesity with inflammation, oxidative stress, insulin resistance, and type 2 diabetes mellitus}

\subsection{Obesity}

Obesity is a medical condition with a major negative impact on health, mainly caused by a series of environmental, humoral, and genetic factors. Within these environmental factors such as the decrease in physical activity, sedentary lifestyle, and increase in foods with a high index [36], this produces a positive energy balance and this excess energy is stored in the form of fat that accumulates in the adipocyte and other organs such as the muscle and liver; however, some individuals are exposed to these factors and do not become obese, suggesting that genetic factors load may predispose individuals to develop obesity [37]. There are genes that have a high capacity to induce a state of obesity. Among them are those that regulate the intake and satiety, such as the gene of leptin or its receptor, alterations in the proopiomelanocortin 
gene or in the melanocortin- 4 receptor, mutations in some of these genes can cause the obesity [38]. On the other hand, investigations of recent years suggest the participation of inflammatory pathways and increased levels of pro-inflammatory cytokines, such as the nuclear factor (NF)- $\kappa$ B resulting in an increase of the IL-6, TNF- $\alpha$, and IL-1 $\beta$ [39], with the development of obesity and obesity-associated insulin resistance, since inflammation caused a significant deterioration in the signaling pathways of insulin and leptin [39-42].

\subsection{Inflammation}

Inflammation is a process of activation of innate immune system, in response to exogenous and endogenous factors, such as infection by microorganisms, tissue stress, and injury [43]. The inflammatory response is characterized by its cardinal signs, such as redness, swelling, heat, pain, and interrupted function [44]. The inflammatory response consists of four main components: (1) endogenous or exogenous factors, such as molecular patterns associated with pathogens (PAMP) and damages (DAMP), which are derived from bacteria, viruses, fungi, parasites, and cell damage, as well as toxic cellular components or any other harmful condition [45]; (2) cellular receptors that recognize these molecular patterns (PRR), including Toll-like receptors (TLRs), nucleotide binding oligomerization domain (NOD)-like receptors (NLR), and retinoic acid inducible gene (RIG)-like receptors [46, 47]; (3) pro-inflammatory mediators, such as cytokines, chemokines, and the complement system [48]; (4) target cells and tissues, where these pro-inflammatory mediators act. The inflammatory response is characterized mainly by four successive phases: (1) silent phase, where the cells synthesize and release the first pro-inflammatory mediators, (2) vascular phase, characterized by increased vascular permeability and dilatation, (3) phase cellular, which is characterized by the infiltration of inflammatory cells to the site of damage, and (4) resolution of the inflammatory response [49-52].

Adipocytes and macrophages of the stromal fraction of adipose tissue express elevated levels of PRRs in response to various stimuli. The activation of PRRs activates a signaling cascade through canonical adapters of receptors, for example, the activation of TLRs that activates myeloid differentiation primary response (MYD)-88 located in plasmatic membrane or in endosomes associated with Toll IL-1r (TIR). This interaction activates a family of kinases which in turn activate different molecules including $\mathrm{NF} \kappa \mathrm{B}$, a primary transcription factor. The translocation of NFKB to the nucleus upregulates the production of INF and inflammatory cytokines, which is an evidence that these receptors play a role in the immune system $[53,54]$.

\subsection{Inflammation and obesity}

The alteration of the metabolic syndrome as a consequence of obesity is one of the most common factors that evoke the activation of inflammation, producing other alterations such as oxidation, cellular hypertrophy, and stress, among others [55].

The metabolic and immune systems are regulated among themselves, and are made up of hormones, cytokines, signaling proteins, transcription factors, and bioactive lipids. The basic inflammatory response therefore promotes a catabolic state and suppresses anabolic pathways, such as the highly conserved and potent insulin signaling pathway $[55,56]$. 
The inflammation attributed to obesity is given by the excessive intake of fats, macro nutrients, and foods rich in antioxidants causing deposition in other organs, mainly in the liver, altering insulin levels. There are other conditions due to obesity, such as alterations in blood pressure, heart rate, respiratory rate, and psychological factors [56, 57].

Obesity causes the increase and the extension of adipose tissue, and molecularly induces the release of signals and protein mediators called adipokines. The inflammatory response is derived from the high production of adipokines that produce the release of inflammatory mediators such as leptin, adiponectin, TNF- $\alpha$, IL-1 $\beta$, IL-6, protein monocyte chemotactic (MCP)-1, macrophage migration inhibitory factor (MIF), NGF, VEGF, plasminogen activator inhibitor (PAI)-1, and haptoglobin [39]. Several studies have shown the expression of these pro-inflammatory mediators (mainly TNF- $\alpha$ and IL-1 $\beta$ ) in metabolic alterations [40].

The increase of evidence in studies of human population and research in animals has established causal links of diseases such as insulin resistance, T2DM, and metabolic syndrome as a result of the increase of adipocytes [40].

A study by Haiyan $\mathrm{Xu}$ et al. demonstrated the active role of macrophages in morbid obesity and the relationship they have with inflammatory processes, concluding that a disease of chronic inflammation initiated in adipose tissue is a consequence of insulin resistance [58, 59]. While it is clear that the inhibition of insulin receptor signaling pathways is a central mechanism by which inflammatory and stress responses mediate insulin resistance, it is likely that other pathways, molecules, and proteins have not been discovered yet with an alternative mechanism involved in this interaction $[59,60]$.

Recent research shows that the main risk to develop a metabolic complication is insulin resistance. However, in addition to cardiovascular and hematological diseases, pathologies such as fatty liver, airway diseases, cancer among other diseases that increase lipid or cytokine levels and, in turn, develop insulin resistance in the absence of obesity are related [61].

It is important to understand the inflammatory pathogenic mechanisms that produce diseases in the absence or presence of obesity. The aim is to reduce the rate of morbidity and mortality by preventing and treating pathologies that link inflammation with obesity [40].

\subsection{Oxidative stress and obesity}

Previous studies have reported and suggested that obesity and oxidative stress have relationship. Some markers of oxidative stress such as malondialdehyde (MDA) are increased in obese people by the production of reactive oxygen species (ROS) and for decrease in activity of antioxidant enzymes such as serum superoxide dismutase (SOD) and catalase (CAT). These factors are involved in the development of oxidation, cell damage, and metabolic diseases [62]. However, other studies suggest that obesity per se can induce systemic oxidative stress through multiple biochemical mechanisms, such as the generation of superoxide, nicotinamide adenine dinucleotide phosphate (NADPH) oxidase, oxidative phosphorylation, glyceraldehyde autoxidation, activation of protein kinase (PK)-C and pathways of hexosamine and polyol. On the other hand, studies suggest that obesity may be caused by oxidative stress through the 
proliferation of preadipocytes and increased size of differentiated adipocytes [63-65]. Obesity is an important risk factor for the development of metabolic syndrome (MetS), diabetes mellitus, dyslipidemia, atherosclerosis, hypertension, insulin resistance, hepatic steatosis, non-alcoholic liver disease, and high morbidity and mortality [66] (Figure 5).

Several investigations and different clinical disciplines in recent years have focused their interest on oxidative stress. This evidence is associated with the pathogenesis of different diseases among which are diabetes, obesity, cancer, aging, inflammation, neurodegenerative disorders, hypertension, apoptosis, cardiovascular diseases, and heart failure [67], and is considered responsible for the beginning and progression of sundry brain disorders that include major depressive disorder [68]. From these investigations appears the concept that oxidative stress is the "common final pathway" through, whereby diseases produce their harmful effects. Oxidative stress causes complex alterations of cell metabolism and cell-cell homeostasis, in particular, oxidative stress is the key in the pathogenesis of insulin resistance and B cell dysfunction as well as in obesity [67].

Janus gas, oxygen $\left(\mathrm{O}_{2}\right)$, has positive beneficial effects as side effects injurious for biological systems. Its reactivity allows oxygen to participate in the transfer of high-energy electrons and therefore generates large amounts of ATP through oxidative phosphorylation. Just as oxygen is essential for life [66] and necessary to allow the evolution of multicellular organisms, it is also capable of attacking any biological macromolecule and the protein, lipid, or deoxyribonucleic acid (DNA) [66, 69], provoking diseases through an uncontrolled production of oxygen free radicals (RLO) and attacking cellular processes (enzymes production and cellular respiration) [66]. These events cause our body subdued to a constant oxidative attack of ROS [69]. Oxidation is the process that is held by the loss of electrons, which is always

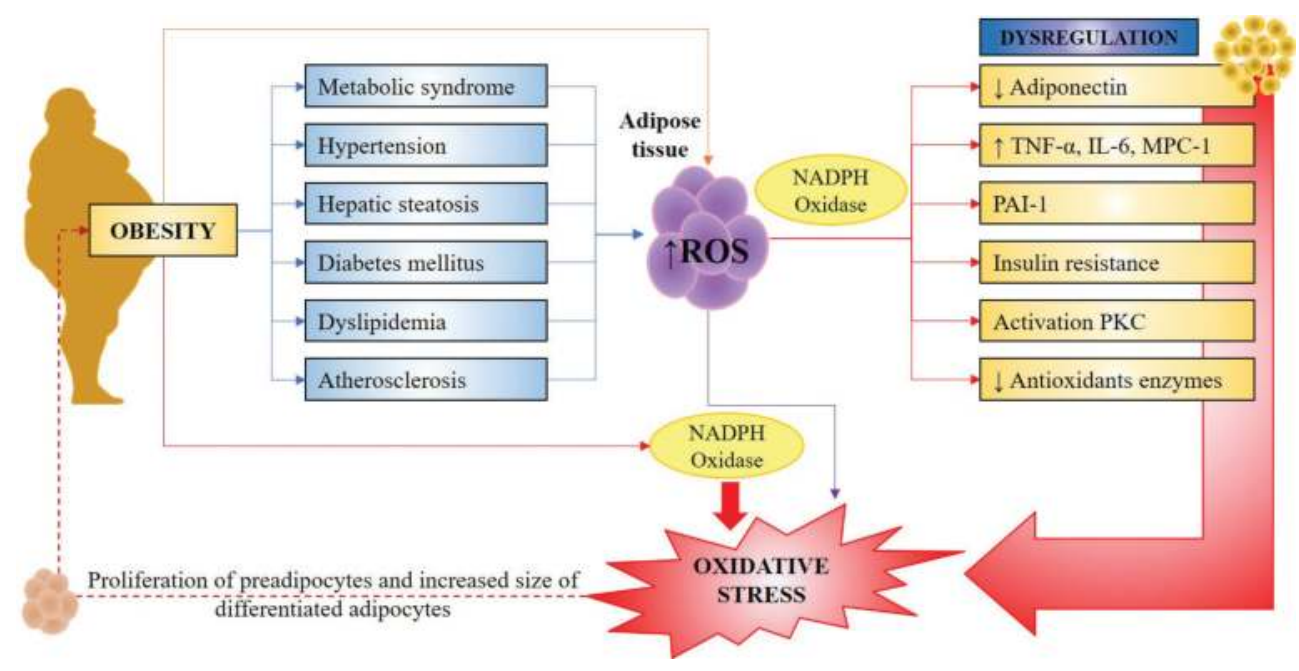

Figure 5. Factors contributing to increased oxidative stress (OS) in adipocytes and linked to insulin resistance, inflammation of adipose tissue, and decreased adiponectin. TNF- $\alpha$, tumor necrosis factor alpha; IL-6, interleukin-6; $\mathrm{MCP}-1$, monocyte chemoattractant protein 1. Description in the text. 
associated with another catchment (reduction). This oxidation is essential for life and participates in processes of obtaining cellular energy [66]. The damage produced by the imbalance between oxidants and antioxidants in favor of oxidants is called "oxidative stress." Oxidants are formed as a normal product of aerobic metabolism, but its production increases rapidly under pathophysiological conditions [70].

Oxidative stress can be defined as the appearance of macromolecular damage from free radicals and thiol alterations that lead to redox control dysfunction [71], where the excess of endogenous oxidative species can damage the cells and manipulate the signaling pathways. Oxidative stress agents that occur at low physiological levels in mitochondria and peroxisomes are: reactive species, ROS such as superoxide, hydrogen, peroxide, and hydroxyl ion radicals. The endogenous ROS that occur at low levels are physiologically important, especially in signaling pathways, although these mechanisms are not yet clear because they perform a double function both as a signal and as a damaging agent. Among these signaling roles are transcriptional control and cell cycle regulation. Oxidative stress occurs when free radical species such as ROS and reactive nitrogen species exceed the capacity of cells to eliminate them through their antioxidant defense mechanisms, which have multiple nocuous effects on the cellular metabolism [65, 72]. It has long been accepted that ROS becomes harmful to cells even at low physiological levels. Recent studies have concluded that ROS damage has a direct role in the development and progression of many chronic diseases, including the pathogenesis of insulin resistance and T2DM [73].

Several studies have reported that obesity is associated with oxidative stress caused by an imbalance related to inadequate antioxidant defenses and an increase in the proportion of free radical formation $[65,74]$. However, other studies suggest that obesity per se can induce systemic oxidative stress through multiple biochemical mechanisms, such as the generation of superoxide NADPH oxidase, oxidative phosphorylation, glyceraldehyde autoxidation, activation of PKC, and pathways of hexosamine and polyol. Hyperleptinemia, tissue dysfunction, low antioxidant defenses, chronic inflammation, and the generation of postprandial ROS are factors involved in the development of obesity in which oxidative stress participates [75] (Figure 5). As the increase in oxidative stress in accumulated fat is, at least in part, the underlying cause of adipocytokine dysregulation and the development of the metabolic syndrome [76], it is known that obesity induces oxidative stress through various mechanisms such as chronic inflammation, endothelial dysfunction, and mitochondrial dysfunction [77].

In vitro and in vivo studies suggest that obesity may be caused by oxidative stress through the proliferation of preadipocytes and increased size of differentiated adipocytes [63,64]. The mass of adipose tissue increases when the pre-adipocytes differentiated in the terminal phase re-enter the cell cycle and undergo proliferation, process called adipogenesis, which includes the proliferation of preadipocytes and their differentiation into mature adipocytes [64]. It has been shown that ROS are implicated in both events. The proliferation of pre-adipocytes activated by ROS participates in the development of metabolic disorders, which generate more ROS through mechanisms that include chronic inflammation of adipocytes, oxidation of fatty acids, excessive oxygen consumption, and accumulation of cell damage, diet, and mitochondrial activity [64, 78]. Abnormal generation of ROS induces cellular dysregulation in many other tissues and promotes obesity [65]. 
The generation of ROS by the accumulation of adipocytes through the activation of NADPH oxidase produces dysregulation of the expression of inflammatory adipocytokines that include adiponectin, PAI-1, IL-6, and MCP-1 and decrease in the production of antioxidant enzymes [71] (Figure 5). Some biomarkers that are known for oxidative stress in serum and urine plasma are: MDA, isoprostanes F-2 (F2-IsoP), Prostaglandin F2a 8-iso (8-isoPGF2a), and carbonylation proteins. A significant positive correlation has been observed between the corporal mass index (BMI) and the biomarkers of oxidative stress [79]. Lower activity of antioxidant enzymes Cu-Zn superoxide dismutase (SOD) [75], Cat [62], and glutathione peroxidase (GPx) has been reported in erythrocytes of obese subjects than in non-obese controls [75, 80, 81].

Obesity is an important risk factor for the development of MetS, diabetes mellitus, dyslipidemia, atherosclerosis, hypertension, insulin resistance, hepatic steatosis, non-alcoholic liver disease, and high morbidity and mortality. Sundry mechanisms may be involved in the development of comorbidity related to obesity, including the abnormal production of adipocytokines, aberrant oxidative stress, and dysregulated pro-inflammatory response in tissues such as muscle and liver. It has been reported that both obesity and oxidative stress can occur in the first two decades of life [82] and accumulated fat is considered an early indicator of the metabolic syndrome associated with obesity which is related to a multitude of different diseases [74]. Therefore, when there is an excess in oxidation, oxidative stress appears which becomes complex at all biological levels since it is not possible to measure it or define it with a single parameter [67]. For all the above reasons, the development of new therapies should be considered as a major objective [76] for the treatment and control of oxidative stress in obesity as well as for diseases in which oxidative stress is involved.

\subsection{Insulin resistance and obesity}

Insulin exerts its effect through binding to its receptor; the insulin receptor (IR) has two isoforms: IR-A and IR-B. IR-A is found mainly in the adult nervous system and has a much higher affinity for insulin than IR-B, and this latter is mainly found in adipose tissue, liver tissue, and skeletal muscle [83]. This receptor is constituted by two $\alpha$ - and two $\beta$-subunits with a molecular weight of $350 \mathrm{kDa}$. The $\alpha$-subunits are located on the outside of the plasma membrane and contain insulin-binding sites, while the $\beta$-subunits have a transmembrane, a juxtamembrane and an intracellular domain, where tyrosine kinase activity is found [84].

Under normal conditions, insulin binds to the $\alpha$-subunit of the IR and promotes the autophosphorylation of the tyrosine residues of the $\beta$-subunit of the receptor. Then, there is a transphosphorylation that is recognized by some adapter molecules, among them are the insulin receptor substrates (IRS), that there are three types and are expressed in humans. IRS-1 and IRS-2 are widely distributed in mammalian tissue, while IRS-4 restricts its expression to the hypothalamus [85], these proteins are adapter molecules for the kinase activity of the phosphorylated insulin receptor, in turn phosphorylating the p85 regulatory subunit of phosphoinositide 3-kinase (PI3K). The phosphorylation of the latter induces a conformational change of this protein which leads to the binding of the catalytic subunit (p110) activating PI3K; once activated, this protein phosphorylates phosphatidylinositol-3,4-diphosphate (PIP2) into the second messenger phosphatidylinositol-3,4,5-triphosphate (PIP3) [86, 87], and these lipid products induce 
the recruitment and the interaction of the protein kinase (PDK)-1 and serine/threonine-specific protein kinase (Akt). The activation of PDK-1 phosphorylates some isoforms of protein kinase $\mathrm{C}$, such as $\mathrm{PKC} \lambda / \zeta$, which is responsible for phosphorylating vesicles that contain the glucose transporter type 4 (GLUT4), promoting migration and fusion with the cell surface, which increases glucose uptake as well as your metabolism [88] (Figure 6A).

As we know, glucose is the main source of energy used by the organism and the only source of energy for the brain. Thus, glucose homeostasis must be finely regulated, and blood glucose levels must be kept within a very defined range $(70-90 \mathrm{mg} / \mathrm{dL})$. When the organism presents obesity, this regulation can be altered together with other factors, then insulin resistance (IR) appears [89]. This alteration is defined as a pathological state where there is a decrease in the metabolic response of target cells, tissue, or the whole organism to the action of insulin. Although acute hyperinsulinemia can be tolerated, chronic hyperinsulinemia exacerbates insulin resistance in different tissues and contributes to the failure of $\beta$ cells to produce insulin and ultimately diabetes is established [90]. Insulin resistance is characterized by a series of alterations at the intracellular level, such as a decrease in the concentration of the receptor and its kinase activity, the concentration and phosphorylation of IRS-1 and IRS-2, PI3K activity, translocation to the membrane of the GLUT4 and the activity of intracellular enzymes [91]. Insulin resistance has been associated mainly with a state of obesity and physical inactivity, as well as a genetic predisposition, the stress on the $\beta$ cells, causing an alteration in the function of these cells and a progressive decrease in the secretion of insulin [92]. IR can be divided into two types: hepatic IR or peripheral RI. Hepatic RI is an altered state of the synthesis of glucose in the liver, while peripheral RI is the reduced response of the skeletal muscle or adipose tissue to the action of insulin [93]. In the muscle, the alterations that contribute to develop RI can be mentioned as defects in: the insulin signaling, in the glucose transporter, in the phosphorylation of glucose, in the synthesis of glycogen, in the activity of the pyruvate dehydrogenase complex and in mitochondrial oxidative activity [94].

On the other hand, hepatic IR increases gluconeogenesis since some substrates (fatty acids, lactate, glycerol and amino acids) are derived from a deficiency of insulin signaling, hyperglucagonemia, and increased sensitivity to glucagon, which leads to increased gluconeogenesis; this overproduction of glucose by the liver occurs in the presence of increased levels of insulin, indicating resistance to insulin-induced suppression of hepatic glucose. This increase may have other factors that contribute to accelerate this production: increased glucagon levels and an increase in liver sensitivity to glucagon; lipotoxicity that induces an increase in the expression and activity of the enzymes phosphoenolpyruvate carboxykinase and pyruvate carboxylase; glucotoxicity that increases the expression and activity of glucose-6-phosphatase [95].

With the development of IR, the $\beta$ cells of the pancreas increase the production and secretion of insulin as a compensatory mechanism (hyperinsulinemia) and the insulin receptor is insensitive to the action of this hormone, increasing the biochemical levels in blood as, glucose, triglycerides, and cholesterol, and lowering high density lipoprotein (HDL) cholesterol; this imbalance contributes to the development of cardiovascular diseases and metabolic syndrome [96]. The prolonged elevation of insulin at systemic level can lead to dysfunction in the signaling of the insulin receptor, mainly of the skeletal muscle, since when it is in a state of 


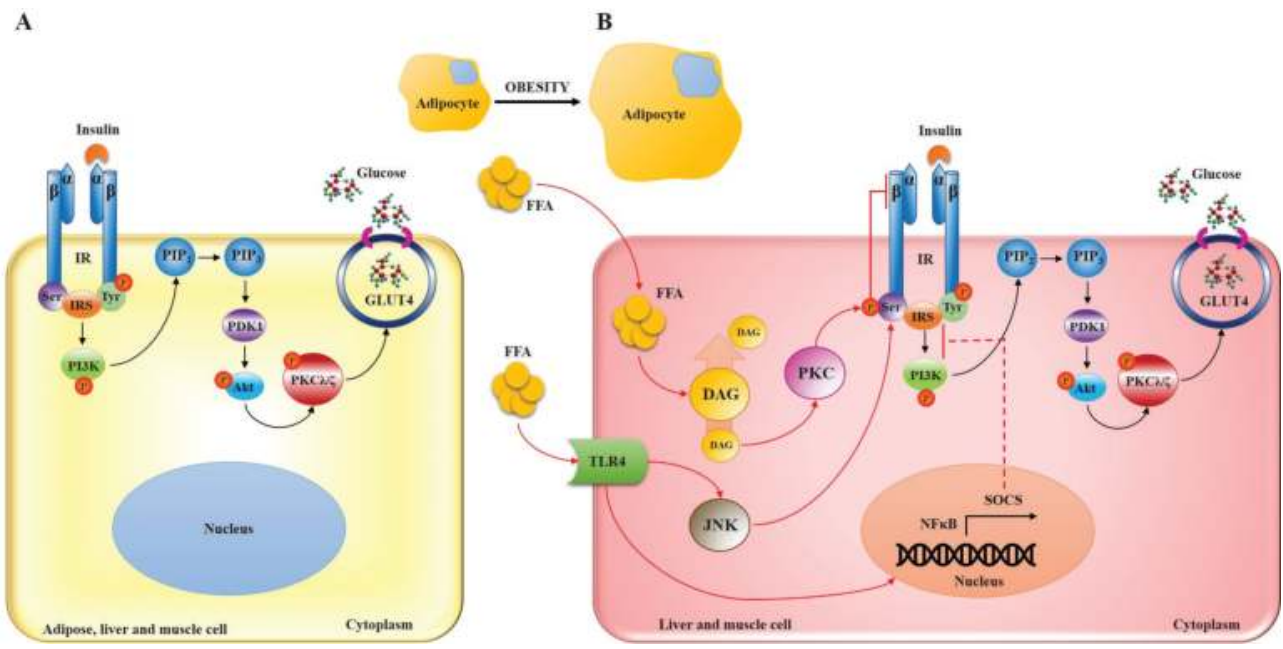

Figure 6. Insulin signaling in normal and obesity conditions. (A) Insulin signaling and glucose production under normal conditions.(B)Insulin resistance and obesity.IR, insulin receptor; IRS, insulin receptorsubstrates; PI3K, phosphoinositide 3-kinase; PIP2, phosphatidylinositol-3,4-diphosphate; PIP3, phosphatidylinositol-3,4,5-triphosphate; PDK-1, protein kinase 1; Akt, serine/threonine-specific protein kinase; GLUT4, glucose transporter type 4; FFA, free fatty acids; DAG, diacylglycerol; PKC, protein kinase C; JNK, C-Jun N-terminal kinases; TLR4, Toll-like receptor 4. Description in the text.

insulin resistance, the synthesis of glycogen is altered due to the decrease in glucose uptake. Insulin loses its ability to lower glucose levels through the transcription factor FOXO1 in the liver because the hormone loses its ability to inhibit this factor, which is involved in regulating gluconeogenesis enzymes. On the other hand, the disruption in the translocation of the GLUT4 glucose transporter from the cytoplasm to the membrane decreases its expression on the membrane, which results in a reduced uptake of circulating glucose.

Insulin resistance is associated with the phosphorylation of the IRS, since there is an increase in phosphorylation in the serine and tyrosine residues (serine/threonine) of this protein, which causes phosphorylation decrease and reduction in the interaction with the PI3K and the Akt, thus decreasing its activity. There is also evidence that adipose tissue plays an important role in the development of insulin resistance, and this tissue can regulate the metabolism of glucose in the body, through the regulation of free fatty acids, the secretion of adipokines, since it acts as an endocrine organ [97]. The ectopic accumulation of lipids in muscle and liver induces insulin resistance through the increase in the levels of diacylglycerol (DAG), and its accumulation promotes the translocation and activation of the protein kinase (PK)-C in the tissues, the PKC- $\theta$ in the muscle, and in the liver the PKC- $\delta$ and PKC- $\varepsilon$, which are involved in inhibiting the kinase activity of the receptor to insulin and thus inhibit insulin signaling [92]. The phosphorylation of IRS- 1 at the residue of Serine- 1101 by PKC- $\theta$ showed a blockade of the insulin-stimulated IRS-1 tyrosine phosphorylation [98]; this determines the signaling of insulin (Figure 6B). In addition to DAG, another fatty intermediate that is involved in insulin resistance is ceramides that can act as a second messenger and can modulate the activity 
of kinases, phosphatases, and some transcription factors. These ceramides reduce the phosphorylation of IRS-1 through insulin and, in turn, are involved in the activation of protein phosphatase (PP)-A2, which can inhibit the phosphorylation of the Akt2 protein in muscle, which influences glucose consumption, since it inhibits the translocation of the GLUT4 glucose transporter to the plasma membrane [99].

Ceramides also activate inflammatory pathways such as c-Jun N-terminal kinases (JNK) and transcription factor NF- $\kappa \mathrm{B}$. The activity of JNK has been related to the pathogenesis of insulin resistance by the phosphorylation of IRS-1 in the Serine-307 residue; when this phosphorylation occurs, the activity in the signaling of the ISR-1 is diminished [100]. Phosphorylation of serine residues has been associated with blocking IRS-1 and inhibiting IR/IRS interaction, thus promoting the degradation of the IRS-1 protein, and thus inducing a lack of insulin response, which generates an insulin resistance.

On the other hand, obesity has been associated with low-grade inflammation, where insulin signaling in the adipocyte and hepatocyte is inhibited through several mechanisms, one of which is the inhibition of IRS- 1 and the signaling cascade of insulin. Another mechanism is the inhibition of peroxisome proliferator-activated receptor (PPAR) $-\gamma$ function; this is a nuclear factor that activates lipid synthesis through inducing enzymes and proteins involved in lipogenesis and fat storage, so that inhibition contributes to insulin resistance [101]. The increase of free fatty acids involve another mechanism where these acids activate some receptors involved in the innate immune response; among these are the TLRs, the medium chain fatty acids that can activate the TLR4 and this in turn initiates the intracellular signaling cascade that culminates in the activation of NF- $\mathrm{kB}$, JNK, and suppressors of cytokine signaling (SOCS) pathways, involved in the activation of inflammatory pathways that induce the expression of inflammatory molecules including cytokines, chemokines, and effectors of the innate immune response; these molecules contribute to insulin resistance associated with obesity [61,99].

In a stage of obesity, macrophages infiltrate adipose tissue and are characterized by an increase in the number of pro-inflammatory M1 macrophages, as well as T helper 1 (Th1), Th17, and $\mathrm{CD}^{+} \mathrm{T}$ lymphocytes. The CD8+ cells play an important role in the differentiation, activation, and migration of macrophages, while $\mathrm{TCD} 4^{+}$lymphocytes and regulatory $\mathrm{T}$ cells are diminished [102]. Macrophages that infiltrate adipose tissue stimulate lipolysis and gluconeogenesis is stimulated through IL-6, thus causing hepatic insulin resistance. The adverse effects of inflammatory cells and mediators on adipocytes is to accelerate the transfer of lipids found in adipose tissue to tissues such as skeletal muscle and liver, which lead to ectopic lipid deposits leading to resistance to the insulin in these tissues causing a metabolic dysfunction [103].

\subsection{Type 2 diabetes mellitus and obesity}

Currently, it is estimated that approximately 415 million people have diabetes, of which more than $90 \%$ have T2MD. However, 318 million people have a preclinical state of impaired glucose regulation $[104,105]$, but intensive pharmacotherapy modifies the patient's lifestyle, since it can reverse or delay the development of T2DM [106, 107]. In humans, obesity is the most common cause for developing insulin resistance, which is a key component in the etiology of T2DM $[108,109]$. 
T2DM has been considered as a metabolic disease. However, investigations of recent years have revealed that the inflammatory responses triggered by the production and the release of adipokines from WAT [110], as well as oxidative stress, are the most important factors related to the development of insulin resistance and the pathogenesis of T2DM [111]. Several investigations [112-116] have reported that the levels of the pro-inflammatory cytokines increase abnormally in both experimental animal models and patients with insulin-resistant and T2DM compared with normal controls, which demonstrates the role of pro-inflammatory cytokines in the development of insulin resistance and the pathogenesis of T2DM $[117,118]$. Among the various pro-inflammatory cytokines, TNF- $\alpha$ is one of the most important pro-inflammatory mediators that is critically involved in the development of insulin resistance and the pathogenesis of T2DM [111, 119]. The elevated level of TNF- $\alpha$ from tissue macrophages [120] induces insulin resistance in adipocytes and peripheral tissues by altering insulin signaling through serine phosphorylation that leads to the development of T2DM [119].

On the other hand, recently, epigenetic factors have been implicated in the regulation of genes that are involved in the development of obesity; these factors are: changes in DNA methylation and microRNAs (miRNAs) expression non-coding miRNAs. Although multiple risk factors have been related to the development of obesity, however, it has not yet been determined how these factors interact with each other in order to develop this disease [121].

miRNAs are a family of small non-coding endogenous RNA molecules approximately 17 to 25 nucleotides in length, which function as epigenetic regulators, modulating gene expression at the post-transcriptional level, without altering the DNA sequence. The miRNAs promotes the association of a protein complex, called the RNA-induced silencing complex (RISC), which directs the miRNAs to their target mRNA. The miRNAs generally bind to the $3^{\prime}$ untranslated region (UTR) of target mRNAs, through base pairing between a small fraction of the miRNA sequence, called the "seed" region composed of 2-7 nucleotides, to decrease gene expression by either of the two post-transcriptional mechanisms: translational repression or rapid degradation of mRNA $[122,123]$.

Apart from their endogenous actions, miRNAs can be secreted into the extracellular space inside nanoparticles called Exos [124, 125]. These Exos contain numerous miRNAs, which can function locally or can enter the circulation to act in different sites. In addition, these Exos can be incorporated into other cells to modulate their function [126, 127].

Finally, a recent study reported that adipose tissue macrophages (ATM) of obese animals secrete Exos that contains miRNAs, which can be absorbed in insulin target cells, both in vitro and in vivo models, resulting in cellular and systemic insulin resistance, as well as intolerance to glucose. In contrast, the treatment of obese recipients with ATM-Exos derived from lean mice leads to an improvement in glucose tolerance and insulin sensitivity, both in vivo and in vitro. This study demonstrated that miR-155 is among the differentially expressed miRNAs in obese ATM-Exos, and that this miR-155 can inhibit insulin signaling and glucose tolerance [128], probably through a mechanism related to the suppression of its target gene peroxisome proliferator-activated receptor (PPAR)- $\gamma$ [129], since when PPAR- $\gamma$ is stimulated, it causes insulin sensitivity; whereas if it is inhibited, it causes insulin resistance [130] (Figure 7). 


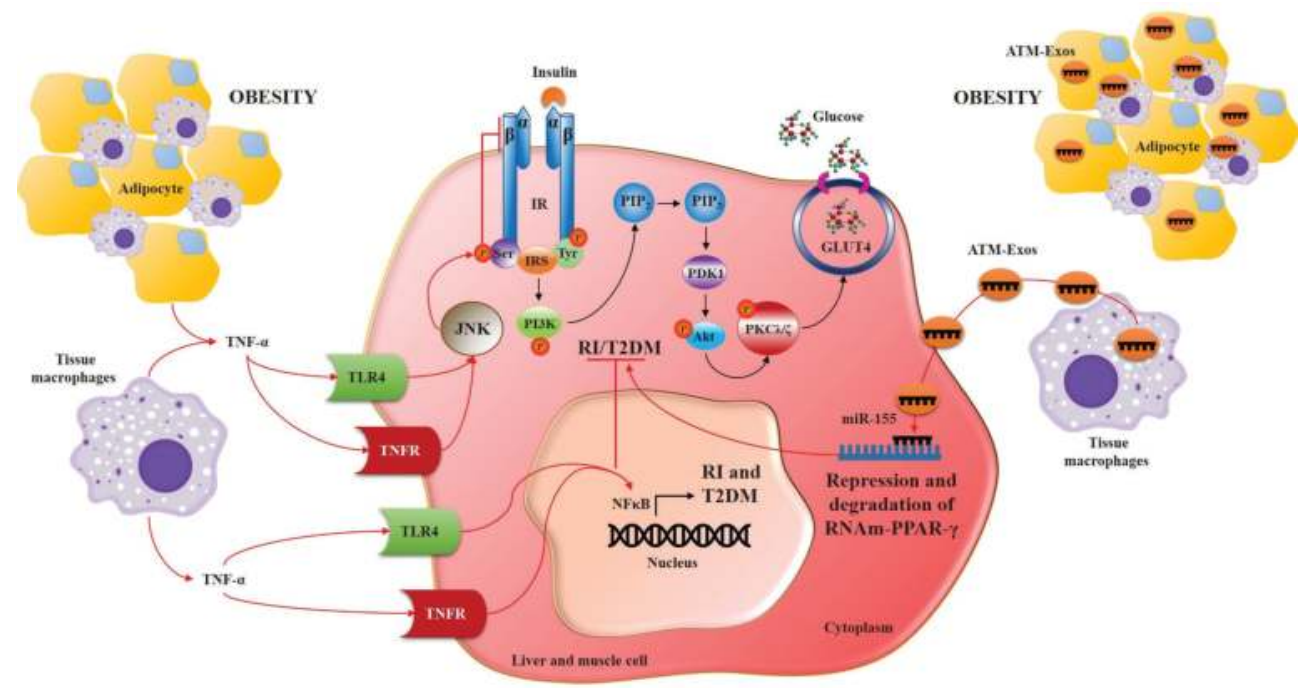

Figure 7. Relationship between type 2 diabetes mellitus and obesity. TNF- $\alpha$ from tissue macrophages induces insulin resistance by altering insulin signaling, which leads to development of T2DM. miR-155 inhibits insulin signaling and glucose tolerance, through of the suppression of PPAR- $\gamma$ IR, insulin receptor; IRS, insulin receptor substrates; PI3K, phosphoinositide 3-kinase; PIP2, phosphatidylinositol-3,4-diphosphate; PIP3, phosphatidylinositol-3,4,5-triphosphate; PDK-1, protein kinase 1; Akt, serine/threonine-specific protein kinase; GLUT4, glucose transporter type 4; FFA, free fatty acids; DAG, diacylglycerol; PKC, protein kinase C; JNK, C-Jun N-terminal kinases; TLR4, Toll-like receptor 4; T2DM, type 2 diabetes mellitus; TNFR, TNF receptor; IR, insulin resistance, PPAR- $\gamma$, peroxisome proliferator-activated receptor- $\gamma$; ATM, tissue macrophages. Description in the text.

\section{Conclusion}

It is very important to understand that adipose tissue is not only a fat storage and insulation organ, but it is an endocrine tissue capable of producing a great variety of molecules, which is associated with other cells and has a close and complex relationship with the immune system. The imbalance in homeostasis, hyperplasia, and overproduction of adipokines leads to pathological conditions, such as obesity and adipose tissue inflammation that can develop insulin resistance and favor the pathogenesis of T2DM.

\section{Acknowledgements}

Thanks to the authors who collaborated in the writing of this chapter: Dr. José Luis Muñoz, Dr. Jaime Ortega, Dr. Oscar Gutiérrez, Dra. Paola Trinidad Villalobos, Dr. Juan Francisco Contreras and Dr. Javier Ventura; as well as the Universities involved: Cuauhtémoc University Aguascalientes, University of Guadalajara, Autonomous University of Nuevo Leon and Autonomous University of Aguascalientes. Thanks for the financial support for chapter publication. 


\section{Conflict of interest}

We have no conflict of interest related to this work.

\section{Author details}

José Luis Muñoz Carrillo ${ }^{1 *}$, Jaime Ortega Martín Del Campo ${ }^{1}$,

Oscar Gutiérrez Coronado², Paola Trinidad Villalobos Gutiérrez², Juan Francisco Contreras Cordero ${ }^{3}$ and Javier Ventura Juárez ${ }^{4}$

*Address all correspondence to: mcbjlmc@gmail.com

1 Faculty of Odontology, School of Biomedical Sciences of the Cuauhtémoc University Aguascalientes, Aguascalientes, Mexico

2 Laboratory of Immunology, Department of Earth and Life Sciences, University Center of Lagos de Moreno of the University of Guadalajara, Lagos de Moreno, Jalisco, Mexico

3 Laboratory of Immunology and Virology, Faculty of Biological Sciences of the Autonomous University of Nuevo Leon, San Nicolás de Los Garza, Nuevo León, Mexico

4 Department of Morphology, Basic Sciences Center of the Autonomous University of Aguascalientes, Aguascalientes, Mexico

\section{References}

[1] Zhang Y, Proenca R, Maffei M, Barone M, Leopold L, Friedman JM. Positional cloning of the mouse obese gene and its human homologue. Nature. 1994;372:425-432. DOI: $10.1038 / 372425 \mathrm{a} 0$

[2] Waki H, Tontonoz P. Endocrine functions of adipose tissue. Annual Review of Pathology. 2007;2:31-56. DOI: 10.1146/annurev.pathol.2.010506.091859

[3] Brooks JSJ, Perosio PS. Adipose tissue In: Sternberg SS editor. Histology for Pathologists. Lippincott-Raven; 1997. pp. 167-196. ISBN: 9780397517183

[4] Symonds ME, Pope M, Budge H. The ontogeny of brown adipose tissue. Annual Review of Nutrition. 2015;35:295-320. DOI: 10.1146/annurev-nutr-071813-105330

[5] Lafontan M. Historical perspectives in fat cell biology: The fat cell as a model for the investigation of hormonal and metabolic pathways. American Journal of Physiology. Cell Physiology. 2012;15:C327-C359. DOI: 10.1152/ajpcell.00168.2011

[6] Alvarez G, Szalowska E, De Vries MP, Weening D, Landman K, Hoek A, Wolffenbuttel BH, Roelofsen H, Vonk RJ. Characterization of the human visceral adipose tissue secretome. Molecular \& Cellular Proteomics. 2007;6(4):589-600. DOI: 10.1074/mcp.M600265-MCP200 
[7] Junqueira C, Carneiro J, Kelley RO editors. Adipose Tissue. Basic Histology. 8th ed. A Lange Medical Book; 1996. pp. 118-123. ISBN: 9780838505670

[8] Cohen P, Spiegelman BM. Brown and beige fat: Molecular parts of a thermogenic machine. Diabetes. 2015;64(7):2346-2351. DOI: 10.2337/db15-0318

[9] Muñoz-Carrillo JL, Muñoz-Escobedo JJ, Maldonado-Tapia CH, Chávez-Ruvalcaba F, Moreno-García MA. Resiniferatoxin lowers TNF- $\alpha$, NO and PGE2 in the intestinal phase and the parasite burden in the muscular phase of Trichinella spiralis infection. Parasite Immunology. 2017;39(1):1-14. DOI: 10.1111/pim.12393

[10] Muñoz-CarrilloJL, Contreras-CorderoJF, Muñoz-López JL, Maldonado-Tapia CH, MuñozEscobedo JJ, Moreno-García MA. Resiniferatoxin modulates the Th1 immune response and protects the host during intestinal nematode infection. Parasite Immunology. 2017;39(9): 1-16. DOI: 10.1111/pim.12448

[11] Hotamisligil G, Shargill N, Spiegelman B. Adipose expression of tumor necrosis factor- $\alpha$ : Direct role in obesity-linked insulin resistance. Science. 1993;59(5091):87-91. DOI: 10.1126/ science.7678183

[12] Duncan RE, Ahmadian M, Jaworski K, Sarkadi-Nagy E, Sul HS. Regulation of lipolysis in adipocytes. Annual Review of Nutrition. 2007;21(27):79-101. DOI: 10.1146/annurev. nutr.27.061406.093734

[13] Jiao P, Chen Q, Shah S, Du J, Tao B, Tzameli I, Yan W, Xu H. Obesity-related upregulation of monocyte chemotactic factors in adipocytes: Involvement of nuclear factor- $\kappa \mathrm{B}$ and c-Jun NH2-terminal kinase pathways. Diabetes. 2009;58(1):104-115. DOI: 10.2337/ db07-1344

[14] Minokoshi Y, Kim YB, Peroni OD, Fryer LGD, Muller C, Carling D, Kahn BB. Leptin stimulates fatty-acid oxidation by activating AMP-activated protein kinase. Nature. 2002;415(6869):339-343. DOI: 10.1038/415339a

[15] Yoon MJ, Lee GY, Chung JJ, Ahn Y, Hong S, Kim JB. Adiponectin increases fatty acid oxidation in skeletal muscle cells by sequential activation of AMP-activated protein kinase, p38 mitogen-activated protein kinase, and peroxisome proliferator-activated receptor $\alpha$. Diabetes. 2006;55(9):2562-2570. DOI: 10.2337/db05-1322

[16] Lago F, Dieguez C, Gómez J, Gualillo O. Adipokines as emerging mediators of immune response and inflammation. Nature. 2007;3(12):716-724. DOI: 10.1038/ncprheum0674

[17] Lee H, Lee I, Choue R. Obesity, inflammation and diet. Pediatric Gastroenterology, Hepatology \& Nutrition. 2013;16(3):143-152. DOI: 10.5223/pghn.2013.16.3.143

[18] Mejhert N, Galitzky J, Pettersson AT, Bambace C, Blomqvist L, Boulomié A, Frayn KN, Dahlman I, Arner P, Rydén M. Mapping of the fibroblast growth factors in human white adipose tissue. The Journal of Clinical Endocrinology and Metabolism. 2010;95(5):24512457. DOI: 10.1210/jc.2009-2049 
[19] Entingh A, Kahn R. Differential roles of the insulin and insulin-like growth factor-1 (IGF-I) receptors in response to insulin and IGF-I. The Journal of Biological Chemistry. 2004;279(36):38016-38024. DOI: 10.1074/jbc.M313201200

[20] Mick GJ, Wang X, McCormick K. White adipocyte vascular endothelial growth factor: Regulation by insulin. Endocrinology. 2002;143(3):948-953. DOI: 10.1210/endo.143.3.8673

[21] Bell LN, Ward JL, Degawa M, Bovenkerk J, Jones R, Cacucci B, Gupta CE, Sheridan C, Shankar S, Steinber H, March K, Considine R. Adipose tissue production of hepatocyte growth factor contributes to elevated serum HGF in obesity. American Journal of Physiology-Endocrinology and Metabolism. 2006;291(4):E843-E848. DOI: 10.1152/ ajpendo.00174.2006

[22] Nisoli E, Tonello C, Benarese M, Liberini P, Carruba MO. Expression of nerve growth factor in Brown adipose tissue: Implications for thermogenesis and obesity. Endocrinology. 1996;137(2):495-503. DOI: 10.1210/endo.137.2.8593794

[23] Lumeng CN, Jennifer L, Bodzin JL, Alan R, Saltiel AR. Obesity induces a phenotypic switch in adipose tissue macrophage polarization. The Journal of Clinical Investigation. 2007;117(1):175-184. DOI: 10.1172/JCI29881

[24] Ouchi N, Parker JL, Lugus JJ, Walsh K. Adipokines in inflammation and metabolic disease. Nature Reviews Immunology. 2011;11(2):85-97. DOI: 10.1038/nri2921

[25] Scheller J, Chalaris A, Schmidt-Arras D, Rose-John S. The pro- and anti-inflammatory properties of the cytokine interleukin-6. Biochimica et Biophysica Acta. 2001;1813(5):878888. DOI: 10.1016/j.bbamcr.2011.01.034

[26] Weisberg S, McCann D, Desai M, Rosenbaum M, Leibel R, Ferrante A. Obesity is associated with macrophage accumulation in adipose tissue. The Journal of Clinical Investigation. 2003;112(12):1796-1808. DOI: 10.1172/JCI200319246

[27] Wing E, Magee D, Barczynski L. Acute starvation in mice reduces the number of T cells and suppresses the development of T-cell-mediated immunity. Immunology. 1988;63(4):677-682. PMCID: PMC1454794

[28] Lumeng C, Del Proposto J, Westcott D, Saltiel A. Phenotypic switching of adipose tissue macrophages with obesity is generated by spatiotemporal differences in macrophage subtypes. Diabetes. 2008;57(12):3239-3246. DOI: 10.2337/db08-0872

[29] Davies L, Jenkins S, Allen J, Taylor P. Tissue resident macrophages. Nature Immunology. 2013;14(10):986-995. DOI: 10.1038/ni.2705

[30] Epelman S, Lavine K, Beaudin A, Sojka D, Carrero J, Brija T, Gautier E, Ivanov S, Satpathy A, Schilling J, Schwendener R, Sergin I, Razani B, Forsberg C, Yokoyama W, Unanue E, Colonna M, Gwendalyn R, Douglas L. Embryonic and adult-derived resident cardiac macrophages are maintained through distinct mechanisms at steady state and during inflammation. Immunity. 2014;40(1):91-104. DOI: 10.1016/j.immuni.2013. 11.019 
[31] Ferrari D, Chiozzi P, Falzoni S, Dal Susino M, Melchorri L, Baricordi O, Di Virgilio F. Extracellular ATP triggers IL-1 beta release by activating the purinergic P2Z receptor of human macrophages. Journal of Immunology. 1997;159(3):1451-1458. PMID: 9233643

[32] Rock K, Lai J, Kono H. Innate and adaptive immune responses to cell death. Immunological Reviews. 2011;243(1):191-205. DOI: 10.1111/j.1600-065X.2011.01040.x

[33] Han SJ, Glatman Zaretsky A, Andrade-Oliveira V, Collins N, Dzutsev A, Shaik J, Morais da Fonseca D, Harrison OJ, Tamoutounour S, Byrd AL, Smelkinson M, Bouladoux N, Bliska JB, Brenchley JM, Brodsky IE, Belkaid Y. White adipose tissue is a reservoir for memory $\mathrm{T}$ cells and promotes protective memory responses to infection. Immunity. 2017;47(6):1154-1168.e6. DOI: 10.1016/j.immuni.2017.11.009

[34] Belluzzi E, El Hadi H, Granzotto M, Rossato M, Ramonda R, Macchi V, de Caro R, Vettor R, Favero M. Systemic and local adipose tissue in knee osteoarthritis. Journal of Cellular Physiology. 2017;232(8):1971-1978. DOI: 10.1002/jcp.25716

[35] Nguyen LT, Sharma AR, Chakraborty C, Saibaba B, Ahn ME, Lee SS. Review of prospects of biological fluid biomarkers in osteoarthritis. International Journal of Molecular Sciences. 2017;18(3). pii: E601. DOI: 10.3390/ijms18030601

[36] Amanda SJ, Toshihiro S, Bruce B. Transgenerational inheritance of prenatal obesogen exposure. Molecular and Cellular Endocrinology. 2014;398(1-2):31-35. DOI: 10.1016/j. mce.2014.09.002

[37] Bray GA, Kim KK, Wilding JPH. Obesity: A chronic relapsing progressive disease process. A position statement of the World Obesity Federation. Obesity Reviews. 2017;18(7):715-723. DOI: 10.1111/obr.12551

[38] Jagriti U, Olivia F, Nikolaos P, Wael G, Christos M. Obesity as a disease. The Medical Clinics of North America. 2018;102(1):13-33. DOI: 10.1016/j.mcna.2017.08.004

[39] De Souza CT, Araujo EP, Bordin S, Ashimine R, Zollner RL, Boschero AC, Saad MJ, Velloso LA. Consumption of a fat-rich diet activates a proinflammatory response and induces insulin resistance in the hypothalamus. Endocrinology. 2005;146(10):4192-4199. DOI: $10.1210 /$ en.2004-1520

[40] Wellen K, Hotamisligil G. Inflammation, stress and diabetes. The Journal of Clinical Investigation. 2005;115(5):1111-1119. DOI: 10.1172/JCI200525102

[41] Lumeng CN, Saltiel AR. Inflammatory links between obesity and metabolic disease. The Journal of Clinical Investigation. 2011;121(6):2111-2117. DOI: 10.1172/JCI57132

[42] Brestoff JR, Artis D. Immune regulation of metabolic homeostasis in health and disease. Cell. 2015;161(1):146-160. DOI: 10.1016/j.cell.2015.02.022

[43] Kotas ME, Medzhitov R. Homeostasis, inflammation, and disease susceptibility. Cell. 2016;160(5):816-827. DOI: 10.1016/j.cell.2015.02.010 
[44] Nathan C. Points of control in inflammation. Nature. 2002;420(6917):846-852. DOI: 10.1038/nature01320

[45] Koenderman L, Buurman W, Daha MR. The innate immune response. Immunology Letters. 2014;162(2 Pt B):95-102. DOI: 10.1016/j.imlet.2014.10.010

[46] Lavelle EC, Murphy C, O'Neill LA, Creagh EM. The role of TLRs, NLRs, and RLRs in mucosal innate immunity and homeostasis. Mucosal Immunology. 2010;3(1):17-28. DOI: 1038/mi.2009.124

[47] Yu L, Yan K, Liu P, Li N, Liu Z, Zhu W, Chen Y, Han D. Pattern recognition receptor-initiated innate antiviral response in mouse adipose cells. Immunology and Cell Biology. 2013;92(2):105-115. DOI: 10.1038/icb.2013.66

[48] Medzhitov R. Origin and physiological roles of inflammation. Nature. 2008;454(7203):428435. DOI: $10.1038 /$ nature07201

[49] Vergnolle N. The inflammatory response. Drug Development Research. 2003;59(4):375381. DOI: $10.1002 / \mathrm{ddr} .10306$

[50] Gilroy DW, Lawrence T, Perretti M, Rossi AG. Inflammatory resolution: New opportunities for drug discovery. Nature Reviews Drug Discovery. 2004;3(5):401-416. DOI: 10.1038/nrd1383

[51] Headland SE, Norling LV. The resolution of inflammation: Principles and challenges. Seminars in Immunology. 2015;27(3):149-160. DOI: 10.1016/j.smim.2015.03.014

[52] Muñoz Carrillo JL, Castro García FP, Gutiérrez Coronado O, Moreno García MA, Contreras Cordero JF. Physiology and pathology of innate immune response against pathogens. In: Rezaei N, editor. Physiology and Pathology of Immunology. InTech; 2017. pp. 99-134. DOI: 10.5772/intechopen.70556

[53] Cuevas A, Lazo M, Zuñiga I, Carrasco F, Potter J, Alvarez V, Berry M, Maluenda F, Ferrario M, Clark J. Expression of MYD88 in adipose tissue of obese people: Is there some role in the development of metabolic syndrome? Metabolic Syndrome and Related Disorders. 2017;15(2):80-85. DOI: 10.1089/met.2016.0104

[54] Muñoz-Carrillo JL, Muñoz-López JL, Muñoz-Escobedo JJ, Maldonado-Tapia C, Gutiérrez-Coronado O, Contreras-Cordero JF, Moreno-García MA. Therapeutic effects of resiniferatoxin related with immunological responses for intestinal inflammation in trichinellosis. The Korean Journal of Parasitology. 2017;55(6):587-599. DOI: 10.3347/ kjp.2017.55.6.587

[55] Monterio R, Acevedo I. Chronic inflammation in obesity and the metabolic syndrome. Mediators of Inflammation. 2010;289645. DOI: 10.1155/2010/289645

[56] Tryhurn P, Wood IS. Signalling role of adipose tissue: Adipokines and inflammation in obesity. Biochemical Society Transactions. 2005;33(Pt 5):1078-1081. DOI: 10.1042/ BST20051078 
[57] Haiyan X, Glenn T, Qing Y, Guo T, Daseng Y, Chieh J. Chronic inflammation in fat plays a crucial role in the development of obesity-related insulin resistance. The Journal of Clinical Investigation. 2003;112(12):1821-1830. DOI: 10.1172/JCI19451

[58] Flores JC, Hirschhorn J, Altshuler D. The inherited basis of diabetes mellitus: Implicatios for genetic analyzuz of complex traits. Annual Review of Genomics and Human Genetics. 2003;4:257-291. DOI: 10.1146/annurev.genom.4.070802.110436

[59] Bastard J, Maachi M, Lagathu C, Kim M, Caron M, Vidal H. Recent advances in the relationshipo between obesity, inflammation, and insulin resistance. European Cytokine Network. 2006;17(1):4-12. PMID: 16613757

[60] Hotamisiligil G. Inflammation and metabolic disorders. Nature. 2006;444(7121):860-867. DOI: $10.1038 /$ nature05485

[61] Shi H, Kokoeva MV, Inouye K, Tzameli I, Yin H, Flier JS. TLR4 links innate immunity and fatty acid-induced insulin resistance. The Journal of Clinical Investigation. 2006;116(11):3015-3025. DOI: 10.1172/JCI28898

[62] Delvarianzadeh M, Abbasian M, Khosravi F, Ebrahimi H, Ebrahimi MH, Fazli M. Appropriate anthropometric indices of obesity and overweight for diagnosis of metabolic syndrome and its relationship with oxidative stress. Diabetes and Metabolic Syndrome: Clinical Research and Reviews. 2017;11(Suppl 2):S907-S911. DOI: 10.1016/j. dsx.2017.07.014

[63] Lee H, Lee YJ, Choi H, Ko EH, Kim J. Reactive oxygen species facilitate adipocyte differentiation by accelerating mitotic clonal expansion. The Journal of Biological Chemistry. 2009;284(16):10601-10609. DOI: 10.1074/jbc.M808742200

[64] Fajas L. Adipogenesis: A cross-talk between cell proliferation and cell differentiation. Annals of Medicine. 2003;35(2):79-85. DOI: 10.1080/07853890310009999

[65] Rani V, Deep G, Singh RK, Palle K, Yadav UCS. Oxidative stress and metabolic disorders: Pathogenesis and therapeutic strategies. Life Sciences. 2016;148:183-193. DOI: 10.1016/j.lfs.2016.02.002

[66] Elejalde Guerra JI. Estrés oxidativo, enfermedades y tratamientos antioxidantes. Anales de Medicina Interna. 2001;18(6):326-335

[67] Pitocco D, Tesauro M, Alessandro R, Ghirlanda G, Cardillo C. Oxidative stress in diabetes: Implications for vascular and other complications. International Journal of Molecular Sciences. 2013;14(11):21525-21550. DOI: 10.3390/ijms141121525

[68] Bengesser SA, Lackner N, Birner A, Fellendorf FT, Platzer M, Mitteregger A, Unterweger R, Reininghaus B, Mangge H, Wallner-Liebmann SJ, Zelzer S, Fuchs D, McIntyre RS, Kapfhammer HP, Reininghaus EZ. Peripheral markers of oxidative stress and antioxidative defense in euthymia of bipolar disorder-gender and obesity effects. Journal of Affective Disorders. 2015;172:367-374. DOI: 10.1016/j.jad.2014.10.014 
[69] Burton GJ, Jauniaux E. Oxidative stress. Best Practice \& Research. Clinical Obstetrics \& Gynaecology. 2011;25(3):287-299. DOI: 10.1016/j.bpobgyn.2010.10.016

[70] Sies H. Oxidative stress: Oxidants and antioxidants. Experimental Physiology. 1997;82(2): 291-295. DOI: 10.1113/expphysiol.1997.sp004024

[71] Kelli HM, Corrigan FE 3rd, Heinl RE, Dhindsa DS, Hammadah M, Samman-Tahhan A, Sandesara P, O'Neal WT, Al Mheid I, Ko YA, Vaccarino V, Ziegler TR, Sperling LS, Brigham K, Jones D, Martin GS, Quyyumi AA. Relation of changes in body fat distribution to oxidative stress. The American Journal of Cardiology. 2017;120(12):2289-2293. DOI: 10.1016/j.amjcard.2017.08.053

[72] Wang J, Yang X, Zhang J. Bridges between mitochondrial oxidative stress, ER stress and mTOR signaling in pancreatic $\beta$ cells. Cellular Signalling. 2016;28(8):1099-1104. DOI: 10.1016/j.cellsig.2016.05.007

[73] Hurrle S, Hsu WH. The etiology of oxidative stress in insulin resistance. Biomedical Journal. 2017;40(5):257-262. DOI: 10.1016/j.bj.2017.06.007

[74] Malti N, Merzouk H, Merzouk SA, Loukidi B, Karaouzene N, Malti A, Narce M. Oxidative stress and maternal obesity: Feto-placental unit interaction. Placenta. 2014;35(6):411-416. DOI: $10.1016 /$ j.placenta.2014.03.010

[75] Manna P, Jain SK. Obesity, oxidative stress, adipose tissue dysfunction, and the associated health risks: Causes and therapeutic strategies. Metabolic Syndrome and Related Disorders. 2015;13(10):423-444. DOI: 10.1089/met.2015.0095

[76] Furukawa S, Fujita T, Shimabukuro M, Iwaki M, Yamada Y, Nakajima Y, Nakayama O, Makishima M, Matsuda M, Shimomura I. Increased oxidative stress in obesity and its impact on metabolic syndrome. The Journal of Clinical Investigation. 2004;114(12):17521761. DOI: $10.1172 / J C I 200421625$

[77] To M, Kono Y, Ogura N, Mikami S, Honda N, Hitani A, Kano I, Haruki K, To Y. Obesityrelated systemic oxidative stress: An important factor of poor asthma control. Allergology International. 2018;67(1):147-149. DOI: 10.1016/j.alit.2017.06.002

[78] Malandrino MI, Fucho R, Weber M, Calderon-Dominguez M, Mir JF, Valcarcel L, Escoté X, Gómez-Serrano M, Peral B, Salvadó L, Fernández-Veledo S, Casals N, VázquezCarrera M, Villarroya F, Vendrell JJ, Serra D, Herrero L. Enhanced fatty acid oxidation in adipocytes and macrophages reduces lipid-induced triglyceride accumulation and inflammation. American Journal of Physiology. Endocrinology and Metabolism. 2015;308(9):E756-E769. DOI: 10.1152/ajpendo.00362.2014

[79] Vincent HK, Taylor AG. Biomarkers and potential mechanisms of obesity-induced oxidant stress in humans. International Journal of Obesity. 2006;30(3):400-418. DOI: 10.1038/ sj.ijo.0803177 
[80] Olusi SO. Obesity is an independent risk factor for plasma lipid peroxidation and depletion of erythrocyte cytoprotectic enzymes in humans. International Journal of Obesity and Related Metabolic Disorders. 2002;26(9):1159-1164. DOI: 10.1038/sj.ijo.0802066

[81] Ozata M, Mergen M, Oktenli C, Aydin A, Sanisoglu SY, Bolu E, Yilmaz MI, Sayal A, Isimer A, Ozdemir IC. Increased oxidative stress and hypozincemia in male obesity. Clinical Biochemistry. 2002;35(8):627-631. DOI: 10.1016/S0009-9120(02)00363-6

[82] Ottobelli Chielle E, de Souza WM, da Silva TP, Moresco RN, Moretto MB. Adipocytokines, inflammatory and oxidative stress markers of clinical relevance altered in young overweight/obese subjects. Clinical Biochemistry. 2016;49(7-8):548-553. DOI: 10.1016/j. clinbiochem.2016.01.003

[83] Neth BJ, Craft S. Insulin resistance and Alzheimer's disease: Bioenergetic linkages. Frontiers in Aging Neuroscience. 2017;9:345. DOI: 10.3389/fnagi.2017.00345

[84] Ye L, Maji S, Sanghera N, Gopalasingam P, Gorbunov E, Tarasov S, Epstein O, KleinSeetharaman J. Structure and dynamics of the insulin receptor: Implications for receptor activation and drug discovery. Drug Discovery Today. 2017;22(7):1092-1102. DOI: 10.1016/j.drudis.2017.04.011

[85] Numan S, Russell DS. Discrete expression of insulin receptor substrate-4 mRNA in adult rat brain. Brain Research Molecular Brain Research. 1999;72(1):97-102. DOI: 10.1016/ S0169-328X(99)00160-6

[86] Patrick P, Yann F, Tuyet TN, Matthias L, Cécile PE, Norbert T, Tarik I. Effect of insulin analogues on phosphatidyl inositol-3 kinase/Akt signalling in INS-1 rat pancreatic derived $\beta$-cells. Archives of Physiology and Biochemistry. 2016;122(2):54-60. DOI: 10.3109/13813455.2015.1125364

[87] Yang Z, Wu F, He Y, Zhang Q, Zhang Y, Zhou G, Yang H, Zhou P. A novel PTP1B inhibitor extracted from Ganoderma lucidum ameliorates insulin resistance by regulating IRS1-GLUT4 cascades in the insulin signaling pathway. Food Function. 2018;9(1):397406. DOI: $10.1039 / \mathrm{c} 7$ fo01489a

[88] Michael PC. Insulin action and resistance in obesity and type 2 diabetes. Nature Medicine. 2017;23(7):804-814. DOI: 10.1038/nm.4350

[89] Abdul-Ghani MA, Tripathy D, DeFronzo RA. Contributions of $\beta$-cell dysfunction and insulin resistance to the pathogenesis of impaired glucose tolerance and impaired fasting glucose. Diabetes Care. 2006;29(5):1130-1139. DOI: 10.2337/diacare.2951130

[90] Fernández-Veledo S, Nieto-Vazquez I, Vila-Bedmar R, Garcia-Guerra L, AlonsoChamorro M, Lorenzo M. Molecular mechanisms involved in obesity-associated insulin resistance: Therapeutical approach. Archives of Physiology and Biochemistry. 2009;115(4):227-239. DOI: 10.1080/13813450903164330

[91] Saltiel AR, Kahn CR. Insulin signalling and the regulation of glucose and lipid metabolism. Nature. 2001;414(6865):799-806. DOI: 10.1038/414799a 
[92] DeFronzo RA, Ferrannini E, Groop L, Henry RR, Herman WH, Holst JJ, Hu FB, Kahn CR, Raz I, Shulman GI, Simonson DC, Testa MA, Weiss R. Type 2 diabetes mellitus. Nature Reviews Disease Primers. 2015;1:15019. DOI: 10.1038/nrdp.2015.19

[93] Xu H, Carrero JJ. Insulin resistance in chronic kidney disease. Nephrology. 2017;22(4):3134. DOI: $10.1111 /$ nep.13147

[94] Samuel VT, Shulman GI. Mechanisms for insulin resistance: Common threads and missing links. Cell. 2012;148(5):852-871. DOI: 10.1016/j.cell.2012.02.017

[95] DeFronzo RA. From the triumvirate to the ominous octet: A new paradigm for the treatment of type 2 diabetes mellitus. Diabetes. 2009;58(4):773-795. DOI: 10.2337/db09-9028

[96] Kang S, Tsai LT, Rosen ED. Nuclear mechanisms of insulin resistance. Trends in Cell Biology. 2016;26(5):341-351. DOI: 10.1016/j.tcb.2016.01.002

[97] Schinner S, Scherbaum WA, Bornstein SR, Barthel A. Molecular mechanisms of insulin resistance. Diabetic Medicine. 2005;22(6):674-682. DOI: 10.1111/j.1464-5491.2005.01566.x

[98] Li Y, Soos TJ, Li X, Wu J, Degennaro M, Sun X, Littman DR, Birnbaum MJ, Polakiewicz RD. Protein kinase $C$ theta inhibits insulin signaling by phosphorylating IRS1 at Ser(1101). The Journal of Biological Chemistry. 2004;279(44):45304-45307. DOI: 10.1074/ jbc.C400186200

[99] Chaurasia B, Summers SA. Ceramides-lipotoxic inducers of metabolic disorders. Trends in Endocrinology and Metabolism. 2015;26(10):538-550. DOI: 10.1016/j.tem.2015.07.006

[100] Ye J. Mechanisms of insulin resistance in obesity. Frontiers in Medicine. 2013;7(1):14-24. DOI: $10.1007 / \mathrm{s} 11684-013-0262-6$

[101] Sah SP, Singh B, Choudhary S, Kumar A. Animal models of insulin resistance: A review. Pharmacological Reports. 2016;68(6):1165-1177. DOI: 10.1016/j.pharep.2016.07.010

[102] Nishimura S, Manabe I, Nagasaki M, Eto K, Yamashita H, Ohsugi M, Otsu M, Hara K, Ueki K, Sugiura S, Yoshimura K, Kadowaki T, Nagai R. CD8+ effector T cells contribute to macrophage recruitment and adipose tissue inflammation in obesity. Nature Medicine. 2009;15(8):914-920. DOI: 10.1038/nm.1964

[103] Wu H, Ballantyne CM. Inflammation versus host defense in obesity. Cell Metabolism. 2014;20(5):708-709. DOI: 10.1016/j.cmet.2014.10.013

[104] International Diabetes Federation. IDF Diabetes Atlas Eighth Edition 2017. Available from: http://www.diabetesatlas.org/ [Accessed 2017 Dec 20].

[105] Chatterjee S, Khunti K, Davies MJ. Type 2 diabetes. Lancet. 2017;389(10085):2239-2251. DOI: 10.1016/S0140-6736(17)30058-2

[106] Knowler WC, Barrett-Connor E, Fowler SE, Hamman RF, Lachin JM, Walker EA, Nathan DM. Reduction in the incidence of type 2 diabetes with lifestyle intervention or metformin. The New England Journal of Medicine. 2002;346:393-403. DOI: 10.1056/ NEJMoa012512 
[107] Taylor R. Type 2 diabetes: Etiology and reversibility. Diabetes Care. 2013;36(4):1047-1055. DOI: $10.2337 / \mathrm{dc} 12-1805$

[108] Romeo GR, Lee J, Shoelson SE. Metabolic syndrome, insulin resistance, and roles of inflammation-mechanisms and therapeutic targets. Arteriosclerosis, Thrombosis, and Vascular Biology. 2012;32(8):1771-1776. DOI: 10.1161/ATVBAHA.111.241869

[109] Johnson AM, Olefsky JM. The origins and drivers of insulin resistance. Cell. 2013;152(4):673-684. DOI: 10.1016/j.cell.2013.01.041

[110] Fantuzzi G. Adipose tissue, adipokines, and inflammation. Journal of Allergy and Clinical Immunology. 2005;115(5):911-919. DOI: 10.1016/j.jaci.2005.02.023

[111] Akash MSH, Rehman K, Liaqat A. Tumor necrosis factor-alpha: Role in development of insulin resistance and pathogenesis of type 2 diabetes mellitus. Journal of Cellular Biochemistry. 2018;119(1):105-110. DOI: 10.1002/jcb.26174

[112] Akash MSH, Rehman K, Sun H, Chen S. Interleukin-1 receptor antagonist improves normoglycemia and insulin sensitivity in diabetic Goto-Kakizaki-rats. European Journal of Pharmacology. 2013;701(1-3):87-95. DOI: 10.1016/j.ejphar.2013.01.008

[113] Memon AA, Sundquist J, Wang X, Palmér K, Sundquist K, Bennet L. The association between cytokines and insulin sensitivity in Iraqi immigrants and native Swedes. BMJ Open. 2013;3(11):e003473. DOI: 10.1136/bmjopen-2013-003473

[114] Rodríguez-Hernández H, Simental-Mendía LE, Rodríguez-Ramírez G, Reyes-Romero MA. Obesity and inflammation: Epidemiology, risk factors, and markers of inflammation. International Journal of Endocrinology. 2013;2013:678159. DOI:10.1155/2013/678159

[115] Donath MY. Targeting inflammation in the treatment of type 2 diabetes: Time to start. Nature Reviews. Drug Discovery. 2014;13(6):465-476. DOI: 10.1038/nrd4275

[116] Kang YE, Kim JM, Joung KH, Lee JH, You BR, Choi MJ, Ryu MJ, Ko YB, Lee MA, Lee J, $\mathrm{Ku}$ BJ, Shong M, Lee KH, Kim HJ. The roles of adipokines, proinflammatory cytokines, and adipose tissue macrophages in obesity-associated insulin resistance in modest obesity and early metabolic dysfunction. PLoS One. 2016;11(4):e0154003. DOI: 10.1371/ journal.pone.0154003

[117] Chen L, Chen R, Wang H, Liang F. Mechanisms linking inflammation to insulin resistance. International Journal of Endocrinology. 2015;2015:508409. DOI: 10.1155/2015/ 508409

[118] Rehman K, Akash MS. Mechanisms of inflammatory responses and development of insulin resistance: How are they interlinked? Journal of Biomedical Science. 2016;23(1): 87. DOI: 10.1186/s12929-016-0303-y

[119] Hotamisligil GS, Arner P, Caro JF, Atkinson RL, Spiegelman BM. Increased adipose tissue expression of tumor necrosis factor-alpha in human obesity and insulin resistance. The Journal of Clinical Investigation. 1995;95(5):2409-2415. DOI: 10.1172/JCI117936

[120] De Taeye BM, Novitskaya T, McGuinness OP, Gleaves L, Medda M, Covington JW, Vaughan DE. Macrophage TNF-alpha contributes to insulin resistance and hepatic steatosis 
in diet-induced obesity. American Journal of Physiology. Endocrinology and Metabolism. 2007;293(3):E713-E725. DOI: 10.1152/ajpendo.00194.2007

[121] Almén MS, Jacobsson JA, Moschonis G, Benedict C, Chrousos GP, Fredriksson R, Schiöth HB. Genome wide analysis reveals association of a FTO gene variant with epigenetic changes. Genomics. 2012;99(3):132-137. DOI: 10.1016/j.ygeno.2011.12.007

[122] Muñoz-Carrillo JL, Sánchez-Rodríguez SH, Aréchiga-Flores CF, Zelmira L, López-Luna A. Identificación de microRNAs en carcinoma cutáneo de células escamosas (CCE). Revista ANACEM. 2013;7(2):108-113

[123] Ohtsuka M, Ling H, Doki Y, Mori M, Calin GA. MicroRNA processing and human cancer. Journal of Clinical Medicine. 2015;4(8):1651-1667. DOI: 10.3390/jcm4081651

[124] Chen Y, Buyel JJ, Hanssen MJ, Siegel F, Pan R, Naumann J, Schell M, van der Lans A, Schlein C, Froehlich H, Heeren J, Virtanen KA, van Marken Lichtenbelt W, Pfeifer A. Exosomal microRNA miR-92a concentration in serum reflects human brown fat activity. Nature Communications. 2016;7:11420. DOI: 10.1038/ncomms11420

[125] Zhang J, Li S, Li L, Li M, Guo C, Yao J, Mi S. Exosome and exosomal microRNA: Trafficking, sorting, and function. Genomics, Proteomics \& Bioinformatics. 2015;13(1):17-24. DOI: 10.1016/j.gpb.2015.02.001

[126] Costa-Silva B, Aiello NM, Ocean AJ, Singh S, Zhang H, Thakur BK, Becker A, Hoshino A, Mark MT, Molina H, Xiang J, Zhang T, Theilen TM, García-Santos G, Williams C, Ararso Y, Huang Y, Rodrigues G, Shen TL, Labori KJ, Lothe IM, Kure EH, Hernandez J, Doussot A, Ebbesen SH, Grandgenett PM, Hollingsworth MA, Jain M, Mallya K, Batra SK, Jarnagin WR, Schwartz RE, Matei I, Peinado H, Stanger BZ, Bromberg J, Lyden D. Pancreatic cancer exosomes initiate pre-metastatic niche formation in the liver. Nature Cell Biology. 2015;17(6):816-826. DOI: 10.1038/ncb3169

[127] Fong MY, Zhou W, Liu L, Alontaga AY, Chandra M, Ashby J, Chow A, O'Connor ST, Li S, Chin AR, Somlo G, Palomares M, Li Z, Tremblay JR, Tsuyada A, Sun G, Reid MA, Wu X, Swiderski P, Ren X, Shi Y, Kong M, Zhong W, Chen Y, Wang SE. Breast-cancersecreted miR-122 reprograms glucose metabolism in premetastatic niche to promote metastasis. Nature Cell Biology. 2015;17(2):183-194. DOI: 10.1038/ncb3094

[128] Ying W, Riopel M, Bandyopadhyay G, Dong Y, Birmingham A, Seo JB, Ofrecio JM, Wollam J, Hernandez-Carretero A, Fu W, Li P, Olefsky JM. Adipose tissue macrophagederived exosomal miRNAs can modulate in vivo and in vitro insulin sensitivity. Cell. 2017;171(2):372-384.e12. DOI: 10.1016/j.cell.2017.08.035

[129] Chen Y, Siegel F, Kipschull S, Haas B, Fröhlich H, Meister G, Pfeifer A. miR-155 regulates differentiation of brown and beige adipocytes via a bistable circuit. Nature Communications. 2013;4:1769. DOI: 10.1038/ncomms2742

[130] Liao W, Nguyen MT, Yoshizaki T, Favelyukis S, Patsouris D, Imamura T, Verma IM, Olefsky JM. Suppression of PPAR-gamma attenuates insulin-stimulated glucose uptake by affecting both GLUT1 and GLUT4 in 3T3-L1 adipocytes. American Journal of Physiology. Endocrinology and Metabolism. 2007;293(1):E219-E227. DOI: 10.1152/ajpendo.00695.2006 
